\title{
Transient Retinal Arterial Occlusion
}

National Cancer Institute

\section{Source}

National Cancer Institute. Transient Retinal Arterial Occlusion. NCI Thesaurus. Code C35193.

A partial, temporary occlusion of the retinal artery. 